\title{
Math Keyboard Symbols and Its Effect in Improving Communication in Math Virtual Classes
}

\author{
R. M. ElSheikh and S. D. Najdi
}

\begin{abstract}
New technologies are rapidly changing our methods of teaching mathematics. Math Communications using special math keyboard symbols can be easily implemented, and promote the professional development of participating teachers. In this paper, a semester-long math virtual class was given at Alquds Open University (QOU) using a math keyboard symbols. Every student had a version of math keyboard and access to the Internet. The main goal was to test if that new technology provides opportunities to expand and enhance communication in virtual mathematics classes introduces though blackboard "elluminate". The results showed that the math keyboard supports the goals of mathematics communication, and contributes to the professional development and best practice of participating teachers and students.
\end{abstract}

Index Terms-Math communication, math keyboard symbols, math virtual classes.

\section{INTRODUCTION}

The rapid development of information and communication technologies especially in the World Wide Web and the internet help universities build up their visions of a virtual university, they want to provide communication facilities, such as; offering their current courses over the internet and making recorded lectures available to students [1].

Hence it becomes necessary to supply QOU educational system, students and faculty members with the necessary tools to deal with these developments and utilize their benefits in teaching and learning.

QOU has increasingly embraced online education, and the number of students enrolled in online programs is rapidly rising, in response to these changes in enrollment demands, the Open Learning Center (OLC) in QOU, has been working on strategic plans to implement online classes in almost every fields of education including Mathematics. At the same time, misconceptions and myths related to the difficulty of teaching and learning online math classes still occurred [2].

Qualitative studies indicate that mathematics does not work well in e-learning [3]. Mathematics presents many unique challenges for online teaching. The most noticeable barrier is communication, since mathematics is a subject heavily laden with symbolism, mathematical representations often involve iconic or pictorial representations that are difficult to create and replicate online, challenging students and teachers to express and exchange mathematical concepts electronically [4].

Manuscriptreceived April 16, 2013; revise June 20, 2013.

R. M. Elsheikh Najdi is with the Department of Education, Alquds Open University, Palestine (e-mail: elnajdi@yahoo.com).

S. D. Najdi is with Alquds Open University, Palestine (e-mail: snajdi@qou.edu).
For the past five years, teachers in QOU faced many difficulties in assessing mathematics online, the abstract nature of the topic, the symbolism and the visual nature of the subject, force them to present their virtual classes using only PowerPoint slides, which contradicts one of the major goals the recent pedagogical insists on, which is to engage students in reflective and collaborative learning, bored students usually drop out of online classes while pleading for richer and more engaging learning experiences [5].

To face some of the revelation that confronts the teachers and students of any online mathematics course. Some teachers used video cameras that allow demonstrations, others create demonstrations using Geometer's Sketchpad, which is a software package allows them to easily compile sketches, graphs, and mathematical expressions. Others used the whiteboard, on the other hand, students still struggle to represent symbols in virtual classes as well as in their typed homework, even with the availability of equation editors and other similar tools, students are unhappy with the time required to learn the software and create symbolic expressions, to solve this, some students simply write the word 'alpha' instead of typing $\alpha$ or 'sigma' rather than $\Sigma$, sometimes students simply search the Web to find solutions to classic problems in mathematics. Many students use graphing calculators that have the capability to allow data and images to be uploaded to a computer and inserted into other documents [6].

In general, students still struggle to represent symbols in their typed math homework, even with the availability of equation editors and other similar tools, students are unhappy with the time required to learn the software and create symbolic expressions, or with the money they spend to buy the graphical calculators and accessories. They simply want to learn how to communicate with the mathematics, not learning how to be Web proficient.

Communication is an essential part of mathematics education. It is the means by which ideas are shared, and a vehicle for clarifying and understanding (NCTM Standards: 2000). Writing in mathematics notation can help students consolidate, reflect and clarify their own work [7].

Mathematical communications rely heavily on symbols. Teachers have difficulty using textual symbols in virtual classes. Math notations in the virtual math classes have no direct support. This makes it exceedingly hard for teachers and students to communicate back and forth with math notations. In some cases instructors have resorted to developing a code for math notation based on the characters available on the keyboard. For example, they would use " $\mathrm{x}^{\wedge}$ $2 "$ to represent $\mathrm{x}$ squared [8].

Teachers and students have difficulty using textual symbols in a virtual class using Blackboard in a quick and 
easy way. In some cases, teachers would incorporate other online tools or environments into their online courses to meet the needs of communicating math notations. However, using more than one math tool is a burden for many online teachers and students. Moreover, many websites with very innovative mathematics tools cannot be used in virtual classes'. In all these situations; the communication of math notation does not have the level of transparency [9].

Research results provide strong evidence that recent live interactive communication, where students must produce unambiguous equations and diagrams quickly is annoying and needs lots of potentials and time [10]. Utilizing animated demonstrations, interactive tools, and especially dynamic tools, both inside and outside of classrooms, is where the most likely benefits of the Internet lie and where the focus of future research might be most fruitful [11].

Often, math interactive tools can, in theory, be recast into dynamic tools using advanced technology. But existing easy alternative can also be possible. We often see websites with very inventive mathematics tools that have not been upgraded to contain current aesthetics or functionality.

The aim of this research was to design a professional math keyboard that can help both teachers and students in typing straight forward math symbols using the keyboard in a speedy ways needed in e-classes. Hence the main question of this research is:

"What is the effect of math keyboard symbols on communicating mathematics in virtual classes"?.

\section{Methodology}

\section{A. Research Method}

Action Research Method was used, which is an approach to improve teaching practice [12]. Action research is a methodology that provides opportunities for reflection, improvement, and transformation of teaching; it is effective in understanding and addressing the particular needs of high need, it goes through series of phases (identify the problem, gather data, interpret data, act on evidence, evaluate results, next steps), Fig. 1, called the Action Research Cycle to systematically [13].

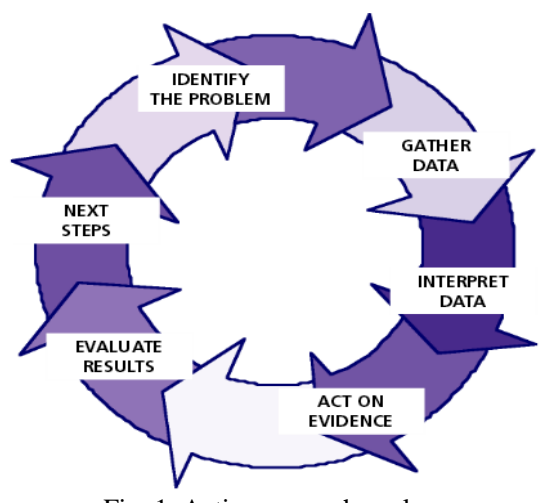

Fig. 1. Action research cycle.

\section{B. Identify the Problem Area}

Teachers often have several questions they wish to investigate; however, it is important to limit the question to one that is meaningful and doable in the confines of their daily work, in this study we limited ourselves to on issue question which was about the best practice teachers can use to revive online math communication. Or what can we do to provide an effective Math Virtual Classes?

Gathering Data

The collection of data is an important step in deciding what action needs to be taken. Multiple sources of data are used to better understand [14]. There are many ways for collection of data; in this study we used the following:

\section{Interviews}

Twelve math teachers from QOU were interviewed; they were asked to answer one question; which is how can we harness all that technology potential for improving the quantity and quality of online mathematical communication, especially in virtual classes?

One teacher mentioned that she has worked extensively on technologies based on Maple and Microsoft Equation 0.3 to solve problems raised on her online courses. Another talked about Math ML and suggested Open Math languages that could allow the inclusion of mathematical formulae on the web pages in a meaningful way. Three teachers declared that, math learning is moving forward, technologies are improving, and student demand is increasing, but few changes are taking place in the structure of virtual classes to accommodate the special needs of the subject. One said technology can help students actually see what a function does rather than have to try and draw a mental image or even worse, plot it out by hand or just accept the idea that something works just because a thick math book says so, the problem is to find the appropriate tool to do so. Almost all of the interviewers agreed on that the virtue classroom requires a user, not a watcher, and there is a great need for an easy communication tool of math notations and diagrams in e-learning that could be used by teachers and students.

\section{Questionnaires}

Using an online survey service provided from OLC, we developed an online questionnaire as an instrument for this survey study. The questionnaire consisted of fifteen questions grouped into three sections related to the current status and future trends of online math education.

The first section included three questions regarding respondents' demographic information. The second section included five questions about the current status of online learning at the respondents' organizations and what's needed to provide a good online math communication. The third section included 5 items regarding predictions about online teaching and learning. The survey used, multiple-choice, and open-ended questions.

The survey took place from late November 2012 to early January 4014. An invitation was sent by e-mail to the sample of QOU teachers. The e-mail included information about the study as well as the URL to the survey site. Of more than 70 who received the e-mail request, 25 completed the survey. The participants responded to the survey anonymously, and the data were stored in the hosted online survey service. Descriptive data analyses (such as frequencies, averages, percentage) were conducted using the data analysis tool provided in the online survey site. The results confirmed some commonly held beliefs about online math education, refuted others, stated some of the tools they believe could facilitate communications in math virtual classes, and 
provided a range of predictions about the future of technology-enabled education. Data was arranged by the most frequent practice mentioned in all these tools and the results came up as illustrated in Table I:

TABLE I: FACTORS THAT WILL MOSTLY AFFECT OF THE COMMUNICATIONS IN ViRTUAL MATH ClasseS

\begin{tabular}{lcc}
\multicolumn{1}{c}{ COMMUNICATIONS IN VIRTUAL MATH CLASSES } \\
\hline Response Option & $\begin{array}{c}\text { Number of } \\
\text { Respondents }\end{array}$ & Response Rate\% \\
\hline $\begin{array}{l}\text { Quick and easy tool } \\
\text { of Math symbols }\end{array}$ & 9 & 45 \\
\hline Graphing tools & 7 & 35 \\
\hline Matrices notation & 3 & 15 \\
\hline Others & 1 & 5 \\
\hline \multicolumn{1}{c}{ Total } & 20 & 100 \\
\hline
\end{tabular}

\section{E. Focus Groups}

Five math teachers from QOU who have been teaching on line math courses for more than three years, formed a focus group, have uncovered substantial qualitative and unpredictable evidence on the difficulties of teaching and learning college mathematics in online environments. They also discussed the reasons behind the complains that they feel and heard of how much online math courses are over whelming, tedious, and unmanageable. They suggested that the problems involve an interaction between mathematics and the online learning modality, and that online learning environments are not well adapted to mathematics

\section{F. Interpret Data}

Existing data indicates that online teachers prefer and tend to use easy to implement tools and strategies, rather than complex programs, simulations, and other forms of rich interactive media. The majority of the respondents expected and wish for easy and time saving tools for math notation, such as key board for math symbols. In addition, our data indicates that graphing tools and matrices notation can develop student collaboration and communication skills

\section{G. Act on Evidence}

Using the information from the data collection and review of current literature, a plan designed to make a change in the situation we chose only one factor that is considered to mostly affect the success of online math communication, since if more than one variable is addressed at the same study makes it difficult to determine which action is responsible for the outcomes[15].

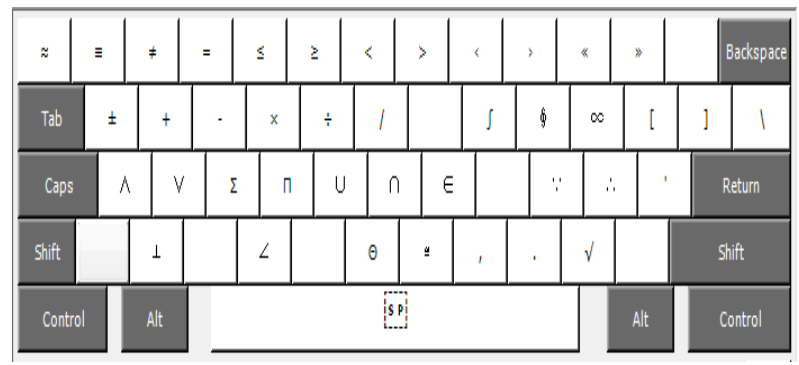

Fig. 2. Math symbols.

To answer the research question, an ordinary keyboard was reprogrammed and designed so that it contained the major symbols a mathematician needs to write a math equation. The symbols on the keyboard were easily used. Math has too many notations to fit on a standard keyboard with 100-odd keys, even with modifiers, so the solution was not to have a huge keyboard with lots of symbols, but one has the basic symbols.

To use this keyboard, you only need to install a $242 \mathrm{~KB}$ program designed for this purpose, then, simply use the ordinary mathematics keyboard above to type your equations. You can use this math keyboard in alternation with your ordinary keyboard, for example you can type regular numbers and letters on your keyboard and use the (shift+ctrl) to type the mathematical characters shown in (Fig. 2).

To type the power of any number, simply hold shift and press the number. To type the Greek characters hold Shift and press the contrast letter in English. As shown in Fig. 3.

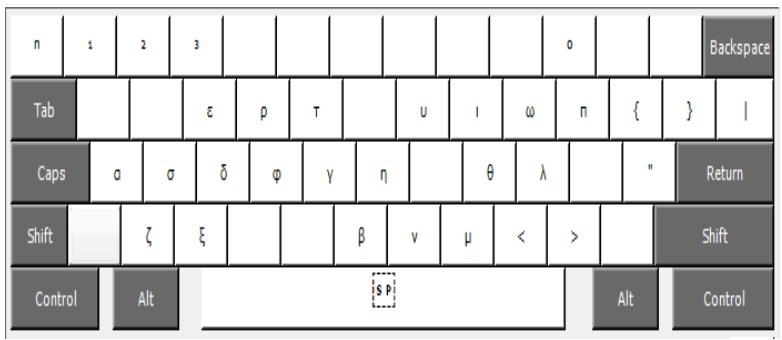

Fig. 3. Greek symbols

After completing the keyboard design, a workshop was given for a sample of five teachers teaching a virtual algebra class in QOU who agreed to use the math keyboard in their e-classes using Blackboard "elluminate" for a full semester. Their e-classes were recorded and analyzed to make sure that the math keyboard was used in an adequate way. The number of times they used the math keyboard were calculated, for example we looked at how many times they used the tools in a one hour lecture. This supports our claim that using the right tools at the right place can make a big difference in communication.

At the end of the experiment, teachers and students were interviewed for feed back of the major strengths and weaknesses.

\section{H. Evaluate Results}

To assess the effects of the intervention to determine if improvement has occurred. After a month of putting the math keyboard in action. Feedback was collected from teachers who used the tool in the online math classes, mainly in virtual classes. Many considered math keyboard is the ideal establishment tool which supports students' needs and encourages motivation; moreover it takes math communication a big step further

"I have just spent few hours going through the tool in more details. I am having absolutely no issues with it. It is doing exactly what it is designed to do. I am really impressed with the changes that have been made to the keyboard".

Another considered math keyboard as teacher-friendly, and added "it's a must for math teachers, its timesaver as I never have to spend valuable minutes going back and forth between math programs".

"Math keyboard is the exact math tool you require for affective virtual classes", one of the teachers added, "it makes writing math symbols as simple as selecting the write button without causing unprofessional embarrassment in e-classes".

Other believed that math keyboard is a perfect addition, but needs more improvements. 
One of the teachers assumed that: "It saves money replacing these expensive utilities students need to buy to submit typed homework".

For more feedback, one virtual math class was recorded on videotape monitoring and counting member of times teacher and students used math keyboard, average of using symbols on math keyboard per page of both teachers and students were calculated as Table II illustrated

TABLE II: NUMBERS OF MATH SYMBOLS WRITTEN BY MATH KEYBOARD IN A Virtual Class Per PaGe

\begin{tabular}{|c|c|c|}
\hline Symbols & $\begin{array}{c}\text { Number of times used } \\
\text { by teacher }\end{array}$ & $\begin{array}{l}\text { Number of times used } \\
\text { by students }\end{array}$ \\
\hline Theta & 7 & 3 \\
\hline$\leq$ & 6 & 2 \\
\hline$\sum$ & 3 & 1 \\
\hline Other & 4 & 2 \\
\hline Average & 5. & 2 \\
\hline
\end{tabular}

Snap shots of math virtual classes with teachers and students using math keyboard are taken, Fig. 4 views the smooth way participants are using the tool.

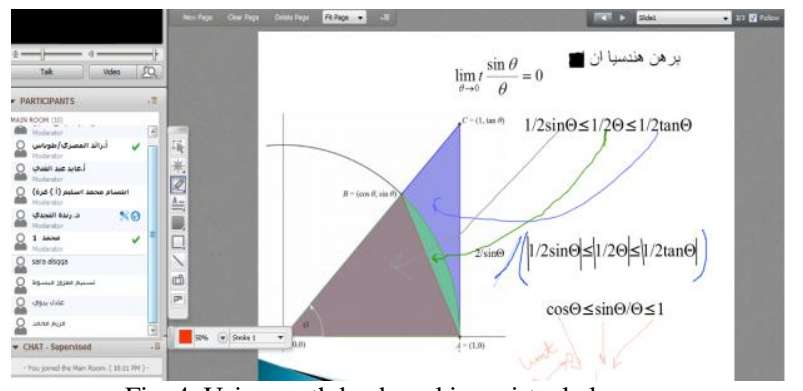

Fig. 4. Using math keyboard in a virtual class.

On the other hands, many teachers pointed out that a noticeable improvement in students' handed homework Fig. 5, and Fig. 6, clearly showed the progress.
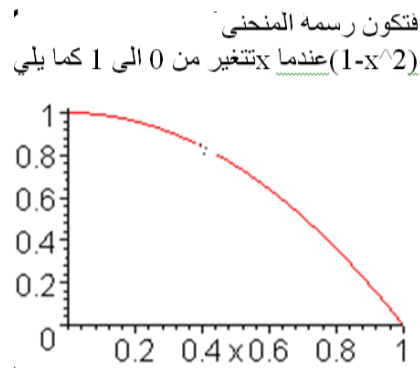

Fig. 5. Student's homework without using math keyboard.

$$
\begin{aligned}
& \iint(\sin x)^{2} d x d y, 0<x<\Pi, 0<y<5 \\
& \int \sin ^{2} x d x=1 / 2 x-1 / 4 \sin 2 x+c, 0<x<\Pi \\
& \text { Fig. 6. Student's homework using math keyboard. }
\end{aligned}
$$

\section{DISCUSSION}

The value of math keyboard were extolled by some teachers and students as being able to do things far better than they would have been able to do otherwise, and also save their time and efforts.
Impact on teachers used the math keyboard symbols was missionary, the tool was considered as a time saving, and they believed that it added a look of proficiency on the virtual classes, which encouraged more students to engage in classes. It also enabled teachers to a quick access, which is considered an indication of better interaction.

Students on the other hand, talked about increased motivation in learning and attending virtual math classes, and made them seem more authentic; it enabled students to visualize mathematical concepts in ways that were previously not easily achieved. One student mentioned that he became better in using e-mail to write questions to teachers, and he has meaningful online communications with his pales.

Finally we can conclude that both students and teachers used the math keyboard tool comfortably in e-classes, which enhanced students' communication and understanding mathematics.

\section{CONCLUSION}

The e-learning environment used in the math courses, has no direct support for math notations and diagrammatic communication, this makes it exceedingly hard for instructors and students to communicate back and forth with math notations. Some students and instructors resort to faxing paper with hand written math notations back and forth, in some cases, instructors would incorporate other online tools or environments into their online courses to meet the needs of communicating math notations. In all of these situations, the communication of math notations and diagrams does not have the level of "transparency" achieved by communication of text [16].

Virtual classes are fast becoming the universal teacher's tool of mathematics teaching (RSC: 2012). Under utilization of math symbols in virtual classes is a common complaint from many teachers and students. From this perspective, a new math symbols keyboard was designed to be used in a quick and easy way which could switch e-classes from static to interactive, allowing both teachers and students to be in control of their learning environment.

The present study confirms math keyboard may have the characteristics of what we call "best practice tool" for interactive web-based mathematics.

\section{ACKNOWLEDGMENT}

Authors would like to express our gratitude to all those who gave us the possibility to complete this report. We are deeply grateful to Omar Najdi who designed the Software needed and helped to a great extent in the project.

\section{REFERENCES}

[1] Information and Communication Technology Center (ICTC), Alquds Open University Co, Jerusalem, 2013.

[2] C. J. Bonk. (2006). The future of online teaching and learning in higher education. Education Quarter, [Online]. 14(5). Available: http://www.educause.edu/ero/article/future-online-teaching-and-learni ng-higher-education

[3] G. Smith and D. Ferguson, "Student attrition in mathematics e-learning," Australian Journal of Educational Technology, vol. 3, pp. 323-334, March 2005

[4] R. Mayes, J. Luebeck, M. Mays, and E. Niemiec. Chapter in Principles of Effective On-line. Teaching, Mathematics On-line: A Virtual Reality or Impossibility, [Online]. 12(4). Available: http://www.iml.sitespace.wvu.edu/r/download/15292. 
[5] C. J. Bonk, "Online Teaching in an Online World," USDLA Journal, vol. 16, pp. 1-6, January 2002.

[6] R. Mayes, J. Luebeck, M. Mays, and E. Niemiec. Chapter in Principles of Effective On-line. Teaching, Mathematics On-line: A Virtual Reality or Impossibility, [Online]. 12(4). Available: http://www.iml.sitespace.wvu.edu/r/download/15292.

[7] A. Juan and A. Huertas, "Teaching mathematics online: Emergent technologies and methodologies," Information Science Reference (an imprint of IGI Global), USA, 2012.

[8] G. Smith, "Student attrition in mathematics e-learning," Australasian Journal of Educational Technology, vol. 3, pp. 323-334, March 2005.

[9] Math on Moodle Sets E-Learning Students, JISC RSC, Verdean college-2012.

[10] J. Portela, "Communicating mathematics through the internet: A case study Educational Multimedia," Interactive Educational Multimedia, ISSN-e 1576-4990, vol. 14, pp. 65-78, April 2007.

[11] C. J. Bonk, "Online teaching in an online world," USDLA Journal, vol. 16, pp. 1-6, January 2002.

[12] A. Juan and A. Huertas, "Teaching mathematics online: Emergent technologies and methodologies," Information Science Reference (an imprint of IGI Global), USA , 2012

[13] E. Ferrance, Action research, Northeast and Islands Regional Educational Laboratory at Brown University, LAB, 2000 Brown University, 2001.

[14] Math on Moodle sets e-learning students, JISC RSC, Verdean college-2012.

[15] J. Portela, "Communicating mathematics through the internet: A case study Educational Multimedia," Interactive Educational Multimedia, ISSN-e 1576-4990, vol. 14, pp. 65-78, April 2007.

[16] C. J. Bonk, "Online teaching in an online world," USDLA Journal, vol. 16, pp. 1-6, January 2002.

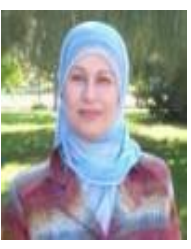

Randa Elsheikh Najdi is an assistance professor of math education at AlQuds Open University, West Bank. She has a PhD and a master in math education (2009) from IRS of Cairo, Egypt. A master degree in pure math from UC Davis at California, USA (1989). She has many certificates in e learning, and won many awards in Teaching Excellence. She is an E learning Expert; she has spent her entire career working in teaching mathematics and has trained a number of teachers in using technology in teaching. Her researches focuses on implementing technology in teaching math, she published number of researches in local and international refereed Journals.

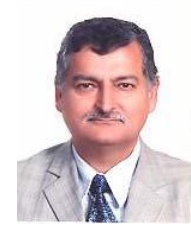

Samir Najdi is a professor, organic and organometallic chemistry. He holds the vice president for Academic Affairs position at Al Quds Open University in Palestine. He earned his BSc in Chemistry from Assuit University (Aswan, Egypt) in 1981, MSc in Organic Chemistry (1984), and PhD in Organomettalic Chemistry (1989) from the University of California at Davis. Prof. Najdi Lectured and taught Chemistry courses at UCDavis, and Al Quds University. He received Fulbright and DAAD Awards, participated as a consultant in international workshops on Leadership, Innovation, and Transformation (Paris, Barcelona, Saint Lucia, Trinidad, Lima, and Jerusalem). His research interests have focused on various aspects; his publications in chemistry focused on Solid phase Polymer-Supported Synthesis, Synthesis of Lactose polymers, C2 Symmetrical molecules which appeared in leading international chemistry journals such as Journal of American Chemical Society (JACS), J. of Organic Chemistry, Tetrahedron, Macromolecules, where as the publications in education on Critical thinking, e-learning, and quality in education appeared in the Palestinian journal of Open and Distance Education, and the Journal of Al-Quds Open University for Research and Studies. 